\title{
Sem modo avião: jovens e leitura de livros, hoje ${ }^{1}$
}

Ana Elisa Ribeiro

Docente do Programa de Pós-Graduação em Estudos de Linguagens do Centro Federal de Educação Tecnológica de Minas Gerais (CEFET-MG). Doutora em Linguística Aplicada pela Universidade Federal de Minas Gerais (UFMG).

E-mail: anadigital@gmail.com

Resumo: Com base em uma concepção de leitura como prática social e inspirado em estudos de história cultural e teorias de letramento, este trabalho traz uma discussão sobre a relação de jovens estudantes de ensino médio, matriculados em uma escola pública federal, com as práticas de leitura - especialmente em relação aos dispositivos mais empregados para o porte e a leitura de textos. Para alcançar o objetivo de conhecer as práticas desse grupo de leitores, foram conduzidos dois grupos focais com estudantes de segundo e terceiro anos no ambiente escolar. Os debates foram gravados em áudio e posteriormente transcritos e analisados. Os resultados apontam para usos não excludentes e bastante diversificados dos livros multiplataforma, contradizendo um discurso polarizador que parece interessar mais à indústria e ao mercado do que ao próprio leitor.

Palavras-chave: livro; práticas de leitura; tecnologias digitais.
Abstract: Based on the concept of reading as social practice and inspired by cultural history studies and literacy theories, this work presents a discussion about reading practices of young high school students of a Brazilian public school, especially regarding the devices most used for carrying and reading texts. To verify the practices of this group of readers, two focus groups were conducted with second - and third - year students in the school environment. Discussions were recorded in audio and later transcribed and analyzed. The results indicate non-exclusive and quite diversified uses of multiplatform books, contradicting a polarizing discourse that seems to be more interested in industry and the market than the people.

Keywords: book; reading practices; digital technologies.
1.Esta é uma versão corrigida e ampliada do artigo que foi inicialmente apresentado e debatido no Grupo de Trabalho Recepção, Circulação e Usos Sociais das Mídias do XXVIII Encontro Anual da Compós, na Pontifícia Universidade Católica do Rio Grande do Sul, Porto Alegre, RS, de 11 a 14 de junho de 2019.

Recebido: 17/06/2019

Aprovado: 02/12/2019 
2.MELLO JÚNIOR, José de. A recepção do e-book no Brasil: uma pesquisa quantitativa com leitores nativos e imigrantes digitais. In: CONGRESSO BRASILEIRO DE CIÊNCIAS DA COMUNICAÇÃO, 39. 2016, São Paulo: Anais [... São Paulo: Universidade de São Paulo, 2016. Disponível em: http://portalintercom org.br/anais/nacional2016/ resumos/R11-2647-1.pdf. Acesso em: 12 maio 2018.

3.Segundo Prensky (2001, p. 1, tradução nossa), os estudantes aos quais ele se refere "hoje", isto é, em 2001, não mudaram apenas seus modos de falar ou vestir em relação a seus predecessores. Há "uma realmente grande descontinuidade" entre essas gerações - isso por conta da chegada das tecnologias digitais nas últimas décadas do século XX. Segundo o autor, os estudantes de "hoje" são "a primeira geração a crescer com essa nova tecnologia. Eles têm gastado suas vidas inteiras rodeados por ou usando computadores, videogames, tocadores de música digitais, câmeras de vídeo, telefones celulares, e todos os outros brinquedos e ferramentas da era digital". Em razão disso, esses jovens pensariam e processariam informações "fundamentalmente diferentemente de seus predecessores", em uma velocidade e de um modo que os educadores não poderiam supor. Prensky cita pesquisadores da área médica e fala inclusive em mudanças na estrutura do cérebro. A partir daí, ele propõe o rótulo "nativos digitais" a esses que são "falantes nativos da linguagem digital de computadores, videogames e da Internet". É importante que estejamos atentos às contas: Prensky incluía entre os tais "nativos" as pessoas que estavam no ensino médio e na gradua ção, na virada do milênio, o que inclui uma população que pode ter hoje cerca de 40-50 anos e todos os que vieram depois.

\section{DISCURSOS E PONDERAÇÕES SOBRE LEITURA E LIVRO: CONSIDERAÇÕES INICIAIS}

O objetivo maior deste trabalho é tecer considerações sobre o modo como jovens estudantes de uma escola pública federal entretecem suas práticas de leitura, em ambientes digitais e impressos, incluindo os dispositivos que usam para isso, a partir de uma investigação que partiu da teoria e foi a campo - a sala de aula -, por meio de grupos focais, a fim de observar e ouvir esses participantes. Várias pesquisas têm sido feitas e relatadas sobre a relação leitor/livro, em particular algumas que buscam conhecer e descrever traços das práticas reais de adolescentes (estudantes da educação básica) e universitários. Os resultados dessas investigações apontam para o mesmo sentido que desejamos discutir aqui. É o caso, por exemplo, da pesquisa de José de Mello Júnior², que investigou mais de 900 estudantes do ensino superior em cinco regiões do Brasil, empregando para isso um método do tipo survey e entrevistas. Após a coleta dos dados, houve tratamento estatístico a fim de demonstrar os usos que os jovens fazem dos dispositivos que escolhem ou podem usar para ler. Mello Júnior se sustenta em classificações de tipos de leitor propostas por Lucia Santaella e na ideia de "nativo digital"3 de Prensky, levantando e testando a hipótese de que os "nativos digitais" seriam mais aderentes às leituras em telas e por meio de dispositivos digitais do que seus antecessores, os "imigrantes digitais", que teriam a cultura do impresso mais arraigada em suas práticas e preferências.

Após essa robusta pesquisa com centenas de jovens universitários e o tratamento dos dados, o pesquisador conclui que "A aderência destes leitores à leitura em telas é baixa, embora utilizem essa modalidade de leitura"4. Mais adiante, o autor afirma que sua investigação

demonstrou não haver diferença estatisticamente significativa entre a amostra de nativos digitais e a de imigrantes, revelando como falsa a hipótese de que o público mais jovem, que cresceu sob a influência dos meios eletrônicos, seria mais aderente a leitura em telas que os imigrantes. ${ }^{5}$

Mello Júnior atribui a lentidão na adesão dos jovens à leitura em telas - e de nossa sociedade em geral - a fatores culturais ligados às "práticas de leitura em papel e seus componentes", o que estaria contendo "o ritmo da introdução

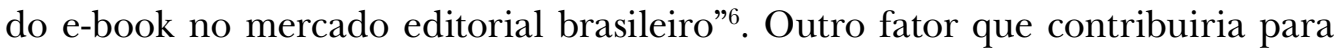
essa lentidão, segundo o pesquisador, seria de caráter econômico, já que o consumo de conteúdo gratuito na internet atrai leitores, mas deprime certos elos da cadeia produtiva do livro. Mello Júnior também aponta para o que chama de "resistência cultural a uma nova tecnologia" como um fator fundamental nesse quadro de aceitação/rejeição das tecnologias digitais para a leitura.

$\mathrm{O}$ autor da pesquisa lembra que o e-book é um formato que existe já há quase cinco décadas, mas continua não ocupando papel hegemônico em nenhum mercado do mundo (em 2016, sem grandes alterações para 2019). "No Brasil sua participação está entre $0,3 \%$ e $2 \%$ do mercado, dependendo da classificação”, afirma ${ }^{8}$. 
Segundo o pesquisador, investigações realizadas com universitários em países como Japão, Alemanha, Eslováquia e Estados Unidos demonstraram resultados semelhantes. E sentencia: "A cultura do impresso resiste mesmo entre aqueles que cresceram imersos na cultura digital" 9 .

Com pesquisa de menor alcance, mas mirando o mesmo tipo de questão, Marina Machiavelli ${ }^{10}$ chegou a conclusões semelhantes às de Mello Júnior. Apoiando-se na noção de mediação de Jesús Martín-Babero e em estudiosos da leitura e da formação de leitores, como a espanhola Teresa Colomer e a francesa Michèle Petit, a investigadora aplicou questionários a 26 estudantes do ensino básico, na cidade de Santa Maria, no Rio Grande do Sul, e analisou dados que a levaram à conclusão de que os jovens ainda preferem ler em papel. Foi o que também apontou André Moraes ${ }^{11}$, após seis anos de um estudo que objetivou conhecer as práticas de leitura de livros por parte de estudantes universitários a partir das indicações de vestibular da Universidade Federal do Rio Grande do Sul (UFRGS). O trabalho de investigação "partiu de questionamentos teóricos a respeito do papel do livro em uma cultura com crescente disponibilidade de outros suportes de conteúdo, como os audiovisuais e os textos eletrônicos" ${ }^{\prime 2}$. A ideia era compreender "o livro dentro deste panorama de pesquisa, mapeando interações e reconfigurações [...]"13.

A "fragmentação das plataformas" era um ponto fundamental na investigação de André Moraes e também é o que podemos verificar aqui, como se verá mais adiante. Após robusto tratamento estatístico dos dados coletados por meio de questionários e entrevistas com jovens leitores, Moraes ponderou que

Embora seja interessante notar que o Livro permaneceu como forma de acesso preferencial e com ampla hegemonia, deve-se pontuar que mesmo esta preferência teve peso sobre oscilações em outras categorias, como ilustrava o caso de um aluno entrevistado que, justamente por preferir leitura em livro, imprimia arquivos eletrônicos quando não tinha acesso aos volumes físicos. ${ }^{14}$

Segundo o pesquisador da UFRGS, "os suportes de leitura e estudo escolhidos pelos estudantes fazem parte de suas táticas pessoais ou grupais, preferências ou conveniências, porém como uma dimensão de apropriação dos meios de comunicação, não numa relação de causa e efeito" ${ }^{15}$. A analogia empregada por Moraes é a dos modais de transporte (ônibus, bicicleta, carro, metrô etc.), que são usados de maneira conveniente, possível e integrada. Os resultados do estudo levaram à melhor noção de um "quadro de usos e hábitos de leitura e estudo por parte dos estudantes que indica ser altamente complexo"16 e é essa complexidade sistêmica que queremos reiterar aqui, com estudantes do ensino médio regular de uma escola pública federal.

André Moraes ${ }^{17}$ descreveu uma "escolha ativa dos canais ou suportes por parte dos alunos" e admitiu que sua pesquisa, "apesar de atuar longitudinalmente acompanhando uma dimensão temporal, ajudou em primeiro lugar a compreender não o futuro do livro ou da leitura, mas o presente da Comunicação"18. Muitos jovens, ao que parece e segundo diversas pesquisas, são ativos na seleção
4.MELLO JÚNIOR op. cit., p. 14.

5.Ibidem, loc. cit., grifos da autora.

6.Ibidem, p. 14.

7.lbidem, p. 14.

8.lbidem, p. 15

9.lbidem, loc. cit.

10.MACHIAVELLI, Marina. A leitura de adolescentes: dados de um estudo exploratório. In: CONGRESSO BRASILEIRO DE CIÊNCIAS DA COMUNICACÃO 40. 2017, Curitiba. Anais [...]. Curitiba: Universidade Positivo, 2017. Disponíve em: http://portalintercom org.br/anais/nacional2017/ resumos/R12-2127-1.pdf Acesso em: 12 maio 2018.

11.MORAES, André Carlos. Leitores multiplataforma: resultados de um estudo longitudinal com estudantes. In: CONGRESSO BRASILEIRO DE CIÊNCIAS DA COMUNICAÇÃO, 40., 2017, Curitiba. Anais [...] Curitiba: Universidade Positivo, 2017. Disponível em: http://portalintercom org.br/anais/nacional2017/ resumos/R12-0739-1.pdf. Acesso em: 12 maio 2018.

12.Ibidem, p. 2 .

13.Ibidem, loc. cit.

14.Ibiden, p. 8.

15.lbidem, p. 13-14, grifos da autora

16.lbidem, p. 14.

17.Ibidem.

18.Ibidem, p. 15. 
19.Ver: RIBEIRO, Ana Elisa. Livro: edição e tecnologias no século XXI. Belo Horizonte: Moinhos, 2018. (Coleção Pensar Edição)

20.Todos os cuidados éticos foram tomados à época, embora a instituição de ensino ainda estivesse im plementando seu conselho de ética oficial, que ainda não operava. Foram enviados e recolhidos termos de consentimento e assentimento, assim como foram preservadas as identidades dos participantes.

21.KIND, Luciana. Notas para o trabalho com a técnica de grupos focais. Psicologia em Revista, Belo Horizonte, v. 10, n. 15, p. 124136, 2004; DUARTE, Adriana Bogliolo Sirihal. Grupo focal online e offline como téc nica de coleta de dados. Informação e Sociedade: Estudos, João Pessoa, v. 17 n. 1, p. 75-85, 2007.

22.Estamos gratas ao auxílio dos, à época, mestrandos Lucas Mariano de Jesus e Flávia Denise Pires de Magalhães, do Posling CEFET-MG na condução e gravação dos grupos. Gratas também à bolsista de Iniciação Científica Fapemig Maria Eduarda Hilarino Drumond, da UFMG, pelas transcrições, fundamentais para este trabalho. Eà inestimável parceira e apoiadora Carla Coscarelli (UFMG), com recursos do projeto "Leitura: modelos, suportes e tecnologias", em que trabalhamos juntas (Fapemig, CHE - APQ-01747-15).

23.CHARTIER, Roger. Cultura escrita, literatura e história: conversas de Roger Chartier com Carlos Aguirre Anaya, Jesús Anaya Rosique, Daniel Goldin e Antônio Saborit. Porto Alegre: Artmed, 2001: Idem, Os desafios da escrita. Tradução: Fúlvia M. L. Moretto. São Paulo: Editora Unesp, 2002.

24.SOARES, Magda. Novas práticas de leitura e escrita: letramento na cibercultura. Educação e Sociedade Campinas, v. 23, n 31, p. 143160, 2002; Idem, Letramento: um tema em três gêneros. 2. ed. Belo Horizonte: Autêntica, 2004. de seus modos e formas de ler, sendo agentes nesse cenário complexo e fragmentado em que é possível integrar meios e práticas.

Subliminar às questões das práticas da leitura e de usos do livro, mas não menos importante, está a definição do que seja o próprio livro, objeto controverso e mutante, implicado em tecnologias e modos de circulação impactados por elas. Neste trabalho, os livros serão todas as materialidades não-periódicas dadas à leitura, impressas (seja por qual técnica for) ou digitais (no suporte que seja), geneticamente ligadas aos processos conhecidos da produção editorial. Uma melhor e mais aprofundada discussão sobre isso pode ser encontrada em Ribeiro ${ }^{19}$, bastando aqui que tenhamos a clareza de incluir sob o nome de "livro" alguns materiais digitais.

\section{DESENHO DA PESQUISA}

A fim de propor uma discussão sobre leitura - na escola e fora dela -, recorremos a um desenho metodológico que permitiu nossa aproximação às práticas de duas turmas de ensino médio (segundo e terceiro anos) de uma escola pública federal. Com o objetivo de coletar um perfil inicial desses estudantes, lançamos mão de um breve questionário padronizado, enviado por e-mail. O documento foi encaminhado aos estudantes via formulário on-line (Google Drive) e foi respondido por 29 adolescentes, que assentiram participar da pesquisa (com consentimento dos pais dos que eram menores de idade) ${ }^{20}$. Os achados permitiram fazer um retrato do grupo pesquisado, sem a intenção de generalização dos resultados, mas, sim, propondo certa noção de tipicidade de suas práticas e discursos. Muito embora o grupo pesquisado seja restrito em relação à juventude geral, é possível presumir, a partir dos dados gerados, situações e questões que atingem alguma parte dos leitores que somos hoje.

Em seguida, os mesmos estudantes foram convidados a participar de grupos focais (GF), o que permitiu uma aproximação mais contundente e um contato efetivo com os participantes da investigação. Conforme recomendam os protocolos descritos sobre esta técnica de geração de dados ${ }^{21}$, as turmas foram divididas em cinco grupos de seis ou sete participantes. Os GF foram conduzidos durante cerca de 1 h30 (cerca de 7 h30 de gravações, no total), acompanhados por mediadores ${ }^{22}$, gravados em áudio e posteriormente transcritos (geraram seis documentos em Word, que, juntos, totalizaram 99 páginas de texto). Com base nessas transcrições, passamos à interpretação dos debates levados a efeito, em salas de aula, durante o horário escolar - preferindo, por questões éticas, não identificar os indivíduos neste texto.

A seguir, apresentaremos dados obtidos com os GF, comentando-os à luz das pesquisas já concluídas por outros pesquisadores e à noção das práticas sociais de leitura, em consonância com estudos, por exemplo, de Roger Chartier sobre história da leitura ${ }^{23}$ e de Magda Soares ${ }^{24}$, sobre letramento, guiadas aqui pelo objetivo de mostrar uma relação destes jovens com as possibilidades de leitura atuais (englobando principalmente as materialidades ligadas ao livro), além, em 
segundo plano, das vivências deles em suas aulas e na escola, considerando-se o uso de tecnologias digitais pelos professores.

\section{JOVENS ESTUDANTES: QUEM SÃO?}

Os jovens participantes desta investigação cursaram o ensino médio em 2018, em uma escola pública federal, o que certamente traz implicações para este perfil: $80 \%$ têm entre 16 e 17 anos, moram com os pais (86\%), a maioria cursava o terceiro ano (80\%, em relação ao segundo); todos faziam, também, formação técnica nas áreas de Trânsito e Eletrotécnica. Em sua maioria, afirmavam raramente ler livros literários impressos $(62 \%)$ ou digitais $(62 \%)$, no entanto, diferia a quantidade de respostas "nunca" nos questionários: $10 \%$ para impressos e $24 \%$ para digitais. $93 \%$ desses jovens têm computador em casa, $100 \%$ têm um smartphone, ao passo que $80 \%$ não têm um tablet. $97 \%$ desses jovens não possui um e-reader, equipamento dedicado à leitura de livros, e alguns sequer sabiam do que se tratava (fato curioso em tempos de disponibilidade tecnológica e acesso a plataformas como a poderosa Amazon).

A despeito de serem jovens de certa faixa distinta de idade, regulares em sua escolarização, habitantes de certa região do país, evitamos um recorte geracional à maneira dos que têm sido produzidos e divulgados por discursos empresariais e de outros campos do conhecimento (por exemplo, Geração X, Geração Y, Millennials e outros), como faz Mello Júnior ${ }^{25}$ ao testar os "nativos digitais" (uma das etiquetas, aliás, mais pregnantes no campo da educação e que não nos parecem ter um efeito importante de fato, para além dos termos que "colam"). Deliberadamente, temos nos distanciado de modelos muito homogeneizantes sobre a juventude, irreais para o contexto brasileiro (ao menos) e que até contraponham jovens e velhos, numa inconciliação entre gerações que nos parece pouco produtiva e bastante preconceituosa. Sem classificá-los, portanto, com uma etiqueta mais generalizante, temos preferido trabalhar com os jovens com os quais nos encontramos, em toda a sua diversidade.

Quanto aos modos de ler, 62\% afirmavam ler textos longos na tela do smartphone, sendo a maioria material didático e notícias de jornais. Quanto aos modos de escrever, o manuscrito continua prevalente (59\%), seguido pelo computador (34,5\%). A escrita à mão é um dado interessante quando pensamos em nossas atividades profissionais atuais, que raramente demandam essa prática, quase totalmente substituída pela escrita por meio de computadores ou teclados. A escola mantém, fortemente, as práticas de anotação e produção de textos manuscritos, geralmente em cadernos de papel.

Foram esses jovens que responderam às questões iniciais a eles propostas nos grupos focais. Vejamos o que essas turmas narraram e comentaram sobre suas práticas de leitura, num cenário complexo de plataformas e opções de leitura. 
comunicação \& educação • Ano XXV • número 1 • jan/jun 2020

\section{4. "O QUE ESTÁ NAS SUAS MOCHILAS HOJE?"}

A primeira pergunta feita aos estudantes que participavam dos grupos focais foi sobre o que carregavam em suas mochilas naquele dia (entre março e abril de 2018, durante o turno escolar). Procurávamos saber se tinham livros impressos, cadernos, apostilas, equipamentos eletrônicos de quaisquer natureza, ou seja: o vestígio das práticas ordinárias e diárias desses estudantes quanto aos materiais de leitura. As respostas deram conta de um quadro previsível: livros didáticos (Física, Biologia, Sociologia), smartphones nos bolsos, cadernos para anotações de aula e, raramente, livros literários (Iracema, de José de Alencar, e Macunaíma, de Mário de Andrade, respectivamente para segundo e terceiro anos).

Um primeiro aspecto que pudemos depreender da conversa com os jovens foi que o livro didático, como sabemos, ainda é majoritariamente impresso. Mais adiante, será possível ver uma conjugação forte entre materiais digitais paradidáticos, mas não exatamente sobre os livros "oficiais" da escola. E, em segundo lugar, mas não menos relevante, uma ideia de que o sinônimo de "leitura" seja a "leitura literária", isto é, só é leitor quem lê literatura - e não qualquer uma, mas a literatura consagrada, canônica ou a que os próprios estudantes denominam "clássica", mesmo quando se referem a escritores brasileiros contemporâneos. Quase se pode supor que "clássico" é o que a escola elege em seu currículo. No entanto, o que é solicitado ou tornado "obrigatório" pela escola é muito diferente do que é lido por "gosto". Essas leituras raramente são as mesmas.

Os estudantes alegaram falta de tempo para ler. Desfiaram um longo rosário de narrativas sobre o excesso de atividades a que são submetidos no ensino de tempo integral (médio + técnico), a quantidade desgastante de tarefas, o cansaço constante, a necessidade de estudar dois turnos e de estudar mais quando chegam em casa. Isso os teria tornado indispostos e cansados para a leitura (entenda-se, de livros literários). Segundo alguns jovens, até o final do ensino fundamental, o gosto pela leitura literária era maior e era possível escolher títulos para ler, pois havia mais tempo administrável e até livre. Depois da entrada no ensino médio/técnico, o tempo "livre" escasseou e foi preciso estabelecer prioridades, entre as quais não figura a literatura: "Foi entrar na escola e abandonar a leitura”, afirmou uma estudante.

Aqueles que gostam de ler relataram uma relação interessada, mas quase abandonada, com o que chamam de "sagas grandes". São citados títulos de escolha como Percy Jackson, biografias, ficção científica, mitologia nórdica e outras obras seriadas. Disse um estudante: "Iracema, Código BRO e Breve história do tempo são os que li mais, em pouco tempo, porque eu queria. Macunaíma foi porque a professora pediu". E essa diferença de agência, de diligência, é fundamental, do ponto de vista dos jovens aqui ouvidos. O querer e o ter de raramente são conciliáveis na escola. Foi curiosa a expressão de outra estudante, ao relatar sua relação com o tempo livre, de prazer e descanso, contra o tempo de leitura escolar: 
Então, o tempo que eu tenho livre ou é pra me dedicar a uma coisa que eu gosto de fazer que é relaxante de verdade ou realmente dormir, sabe? Ou fazer uma coisa que não exige da cabeça. [...] Então, não tem muita dessa opção de eu gosto de ler esse tipo de coisa no ônibus, eu gosto de ler esse tipo de coisa em casa. É aquele negócio, assim, eu tenho que ler Macunaíma pra prova de semana que vem, entendeu? Então, eu deixo de ler as coisas que eu quero pra ler a tal da Macunaíma. Então, é questão de desvestir um santo pra vestir o outro, sabe? Eu acho que nas férias cabe aí o livro que a gente quer ler. $\mathrm{Eu}$, pelo menos, não tenho muitas opções, não. É fazer o que eu preciso fazer e é isso aí! (estudante do $2^{\circ}$ ano)

Com uma carga de estudos tão pesada, foi comum os jovens dizerem que passam as férias e o tempo de descanso sem querer sequer olhar para um livro. Segundo um dos rapazes, "Você tem que se esforçar para ter um tempo para ler", o que nem sempre é feito ou é preferido.

A imposição da leitura e a escolha dos títulos foi motivo de debate entre os estudantes, embora eles não chegassem a reclamar do que a escola propõe, inclusive elogiando iniciativas de instituições de ensino fundamental que tinham projetos rigorosos de leitura semanal de livros. Eles sabem que isso pode fazer diferença positiva e tal fato parece ser um ponto pacífico. É como se esperassem mesmo da escola que ela estivesse no rol das coisas que eles não fariam por conta própria. Na literatura, os jovens dizem que ela indica a "literatura antiga" e a "literatura brasileira", quase sinonimamente. Já os livros de escolha, de prazer, seriam majoritariamente de autores estrangeiros, preferencialmente americanos, mencionando-se as tais "sagas" e livros que "se parecem filmes". Disse um aluno sobre a relação subjetiva com a leitura: "Por exemplo, igual ao Iracema... eu sei que é pequeno, não chega nem a cem páginas, mas, pra mim, é grande, porque eu não quero ler, entendeu?”. Mede-se um livro e uma leitura, portanto, em gosto/desejo, não em páginas.

Alegando a necessidade de uma "maturidade literária” para ler títulos indicados, especialmente brasileiros, relatou uma aluna:

Eu não consigo ler coisa muito antiga. Tentei ler Machado de Assis três vezes e sempre paro no meio. Não consigo continuar. Então, tipo assim, eu pego o livro e falo: não, agora eu vou ler, eu tenho que ler, todo mundo fala, é importante pegar uma literatura. Mas o Brás Cubas mesmo eu não consigo continuar. (estudante do $2^{\circ}$ ano)

Entre os motivos da dificuldade estaria a "linguagem difícil", argumento e impressão com que muitos concordaram. Ainda assim, grande parte dos jovens ouvidos tem uma relação simbólica positiva com o livro impresso, embora seja também uma relação sociologicamente curiosa, como veremos mais adiante.

Estão, portanto, nas mochilas desses estudantes de ensino médio de escola pública federal os materiais de que eles precisam no dia de aula, algum livro, geralmente didático, e seus celulares, fonte de também grande parte do que usam para estudar e ler. 
É interessante pensar que essas mochilas cheias e pesadas acompanham esses rapazes e essas moças ao longo da semana, todos os dias. Com elas, eles cruzam a cidade e passam o dia fora de suas residências, portanto levam nessas bolsas tudo o que pensam precisar para viver por muitas horas na escola, incluindo-se materiais obrigatórios ou não. Estão computadas ali suas horas de descanso, cochilo, lazer, prazer e deslocamento. O contexto escolar certamente dirige nossos achados, o que não nos parece um efeito ruim para uma abordagem do livro e da leitura cotidianos.

\section{5. "NOS DESLOCAMENTOS PELA CIDADE"}

A pergunta que se seguiu àquela sobre o material de leitura na mochila foi a respeito do que esses estudantes fazem durante seus deslocamentos pela cidade, em especial de casa até a escola e vice-versa. Parte desses jovens morava longe da instituição, em cidades da região metropolitana de Belo Horizonte, havendo relatos de que levavam até duas horas no trânsito, o que os obrigava a uma rotina realmente longa fora de casa. Nesse tempo de deslocamento, grande parte deles disse não ter condição de ler, em razão de estarem sempre cansados, com sono ou em transporte público lotado, às vezes de pé. Outras justificativas para não ler durante o deslocamento pela cidade foram que: "dói a vista" ou a cabeça, "sacode demais", as pessoas falam ao redor, desconcentra, "embaralha a vista", "dá enjoo", aumenta o sono. Embora possam parecer banalidades, essas justificativas não são desprezíveis, já que funcionam como critérios ou como determinantes do que fazer em viagens. Alguns estudantes disseram preferir ler em casa, com ambiente e luz apropriados, embora isso quase sempre dissesse respeito às leituras técnicas e didáticas.

O livro literário, portanto, que não cabia nem nas aulas, nem em casa, nem no deslocamento, talvez fosse objeto de leitura nas férias, em poucos casos. Como disse uma aluna, em tom de defesa, ao confessar que leu livros que tomou emprestados nas férias: "Li, pode me julgar! Levei livros para a casa dos meus pais, levei livro pra praia. Eu li, gosto muito". Outro aluno assim resumiu o tempo do livro literário: "nosso momento de leitura é isso... é quando a gente não tem nada pra fazer". E esse "nada" a que ele se referia precisa ser radical. Complementaram outros alunos que ler um livro é caso extremo. Por exemplo, quando não há wi-fi disponível. Disse uma estudante:

Nessas férias eu não li não, mas nas outras eu tinha costume de ler. Até, tipo, hoje em dia assim, em período de aula, tem vezes que, por exemplo, acaba o wi-fi, cai a internet, aí eu vou lá, pego um livro assim, dou umas folheadas. Aí marco a página pra depois ler, continuar a ler, só que só vou ler de novo quando o wi-fi cai de novo. [...] ou então quando viaja e, sei lá, cê vai pra uma casa que não tem internet, um sítio. Aí cê leva um livro, nossa!, cê até inventa o livro, cê escreve, sei lá, nossa, é tão... fica tão ocioso seu tempo que você não tem nada pra fazer. (estudante de $3^{\circ}$ ano) 
Embora o livro e a literatura estivessem sempre no horizonte do desejável e do escolar, notava-se, no debate entre estes jovens, que o valor dificilmente corresponde à prática. E há muito o que fazer, como prioridade, a não ser que o wi-fi finalmente caia. E ainda assim, será?

\section{LIVROS IMPRESSOS E LIVROS DIGITAIS: TEMPOS E ESPAÇOS}

O que nos interessava mais de perto nesta investigação era a relação que os jovens estudantes tinham (e têm) com livros impressos e digitais. Assim que entramos nesse tema, dissipou-se, de fato, a lenda de que eles fariam parte de uma geração avessa ao papel e totalmente afim com tecnologias digitais, inclusive para a leitura (de livros). Os "não" veementes em relação a frases que denotassem preferência por e-books ou PDFs, por exemplo, já nos diziam muito.

A assunção imediata, nos grupos focais, de um trato mesclado, interpolado, com livros de papel e celulares (tecnologia preferencial para leitura) trouxe então uma discussão sobre as razões e os critérios que os faziam preferir ler um livro impresso ou um PDF. Tablets e e-readers não foram equipamentos preferenciais, sendo que a maioria desses jovens nem os tem. Computadores de mesa e notebooks são possíveis, mas não foram os favoritos na hora de ler, embora alguns estudantes apontassem uma preferência por ler textos grandes em telas maiores. O aparelho de telefone foi mesmo o suporte mais usado para leitura, fosse ela uma demanda escolar ou não.

As razões pelas quais os jovens participantes liam no celular compõem uma pequena lista, em ordem decrescente de importância e relevância, conforme o que disseram:

1. custo mais baixo (geralmente, não é preciso pagar pelos pdfs e livros);

2. praticidade (está sempre à mão);

3. atende melhor em casos de urgência (prazos apertados);

4. são mais leves de carregar do que livros e;

5. não dão o trabalho de ir até uma biblioteca ou livraria.

Houve preferências em relação aos ambientes de leitura, isto é, "celular na rua, impresso em casa”, mas vários estudantes apontaram o contrário, devido ao medo de serem assaltados com seus aparelhos na rua e no transporte público. No uso dos celulares, houve preferência por textos curtos, como notícias e crônicas, sendo o "textão" algo a se evitar (há até "alerta sobre textão").

As razões para não usar os smartphones para leitura, especialmente a de livros, também foram muitas - da mais para a menos citada: 


\section{comunicação \& educação • Ano XXV • número 1 • jan/jun 2020}

26.A questão controversa da obsolescência programada pode ser vista, por exemplo, em: FITZPATRICK Kathleen. Planned obsolescence: publishing, technology, and the future of the academy. New York: NYU Press, 2011

\section{MORAES, op. cit.}

28.Este é um aspecto tratado em Chartier (2002) como muito relevante em relação às diferenças entre livros impressos e digitais.

29. Temos evitado tratar essas questões dessa maneira simplista, como casos de vantagem e desvantagem. Preferimos falar em "movimentos", como explicado em Ribeiro (2018).
1. muito maiores as chances de distração, desconcentração (por conta de aplicativos abertos, mensagens a todo momento);

2. necessidade de dar zoom sempre para aumentar os textos;

3. "dor nas vistas";

4. tela clara demais;

5. risco de assalto.

A necessidade, imposta pelo mercado, de trocas constantes de aparelhos também foi um ponto negativo do uso do equipamento (obsolescência programada ${ }^{26}$ ). O aumento do tempo de leitura, em razão dos distratores, foi o elemento mais mencionado como problema e empecilho para a leitura de livros nessas telas. Resumiu um estudante: "Por vontade própria eu não leio em digital".

No entanto, essas vantagens e desvantagens foram justamente os pontos sentidos como complementares na hora de escolher entre ler em papel ou em pixels. A percepção de todas essas questões compõe um quadro complementar, no geral afastando a ideia de uma concorrência exclusivista, como fazem parecer algumas teorias, que, de resto, nos parecem cegas e surdas para as práticas sociais reais, muito mais diversas e interpoladoras. Lembrar Moraes ${ }^{27}$ (2017) e complementá-lo é relevante aqui: conveniência e preferência, conforme a oportunidade. Pode-se dizer, com inspiração em Michel de Certeau, que as práticas de leitura são táticas, ao menos para esses jovens.

Além de, às vezes, imprimirem material digital para ler, os estudantes apontaram razões para escolherem o livro impresso em momentos alternados com tecnologias digitais - também do mais para o menos citado: o fato de ser um dispositivo dedicado, sem interferências de mensagens etc., aumenta a concentração, quando é momento de estudar ou ler prestando atenção exclusiva; além disso, os livros impressos são apontados como mais adequados à leitura de textos grandes, assim como mudam a relação e as percepções do leitor, isto é, o dimensionamento do volume (de páginas, de texto, quanto falta, quanto já foi lido ${ }^{28}$ é mais preciso, além de ser mais prazeroso. Nesse último item, vários jovens repetiram um discurso muito familiar sobre a materialidade: livro de papel é melhor de tocar, de passar páginas, de cheirar e de marcar texto/comentar.

Embora tenham admitido que constituem o hábito conforme a necessidade, os estudantes disseram que quando é preciso "focar mesmo", o papel se presta melhor à tarefa. Segundo um aluno: "Livro digital só em caso de emergência". Exatamente coladas nas "vantagens" do digital, as "desvantagens" do livro impresso $^{29}$ cederam espaço à conciliação e às práticas alternadas. Segundo os jovens participantes desta pesquisa, o livro impresso é mais caro, mais pesado e mais trabalhoso, no sentido de consegui-lo. É preciso ir a livrarias e bibliotecas, o que nem sempre é satisfatório ou possível. Foram mencionadas, além das livrarias de redes mais famosas, os sebos, inclusive virtuais, e as bibliotecas escolares, geralmente criticadas por manterem exemplares em número insuficiente e em más condições de conservação. O livro impresso, ainda assim, foi considerado mais confortável para a leitura. 
Em relação ao valor simbólico, o livro impresso continuou em primeiro lugar, embora alguns estudantes reconhecessem o fato de vivermos em uma época de transição, ou seja, de mudança de tecnologias, da herança de hábitos tradicionalmente impressos para práticas com tecnologias digitais. Para alguns desses jovens, as próximas gerações terão menos apego ao impresso e tratarão o digital como normal, preferencial, em consonância com o que Mello Júnior ${ }^{30}$ encontrou em seus estudos. Ainda assim, nossos estudantes não creem na substituição completa do papel. Segundo resumiu um aluno, o livro não tem sido excluído, mas passou ao status de raridade.

A leitura de livros em dispositivos digitais foi considerada ainda secundária em alguma medida porque, segundo uma estudante, não parece que se está lendo "um livro de verdade". O impresso e sua materialidade têm alto valor simbólico, estando a cultura e a erudição fortemente ligadas a esse objeto. Ser culto é ler livros de papel, em quantidade considerável. Segundo esses jovens, dá status de "culto" tirar fotos perto de livros, ter consultórios e escritórios cheios de estantes repletas de lombadas, etc. O livro físico seria uma tecnologia "mais imersiva", de alto valor agregado. No livro impresso, aprende-se mais, justamente porque eles convidam ao passeio, à trajetória, à experiência com as páginas, ao flanar. Ao procurar informações, é preciso folhear; e, ao folhear, aprende-se mais do que o que se procura simplesmente. O exemplo de um aluno foi o do dicionário impresso: a cada palavra procurada, aprende-se ao menos mais cinco ou dez das que estão ao redor. Isso não ocorre, segundo ele, nos dicionários digitais, que mostram apenas a palavra buscada.

Por essas razões, o valor (preço) mais alto do livro de papel até se justificaria, segundo esses jovens. Há mais valor simbólico e financeiro. E quando é o momento de comprar um livro ou baixar um PDF? De acordo com o valor que se dá à leitura daquele livro, em específico. Um livro obrigatório, mas que não se deseja ler, vale um PDF. Se for objeto de desejo, sim, é possível comprar um livro impresso, pelo qual se pagará mais. A questão, portanto, é de valor, não de preço. E qual é o valor da leitura literária para esses estudantes?

Como se escolhe um livro para ler por vontade própria? Onde e como se cria o hábito de ler? Segundo esses jovens, o hábito precisa nascer dentro da pessoa. Sem mediação, talvez. Eles não parecem considerar que a mediação auxilie na formação do desejo de ler ou do gosto. Nas raras vezes que visitaram livrarias e feiras (ou bienais, conforme citaram), o que os atraiu foi a forma do livro, mais precisamente a capa. No entanto, se o conteúdo de um livro impresso for o mesmo de um PDF, a depender do valor simbólico atribuído àquela leitura, o jovem preferirá não pagar por um impresso e apenas cumprir a atividade da maneira mais fácil e mais barata possível. Disse uma aluna que pegar um PDF é "dar de espertinho", e que alguns colegas pegam por questão de custo e de "valer a pena"; outros preferem ter o livro de papel, se puderem.

Muito embora tenham forte apreço por seus celulares, os estudantes ainda se ressentem do que acontece aos livros impressos. Falaram de uma "dorzinha" que dá quando veem livros sendo queimados ou jogados fora; mencionaram a 
substituição total de enciclopédias de papel por digitais e buscas na Wikipédia ou no Google; afirmaram que livros baixados no celular são prontamente apagados depois de lidos, a fim de "liberar memória, senão enche”. Já os livros impressos não são jogados fora e passam a fazer parte de acervos particulares ou são emprestados a novos leitores. Disse um estudante, de modo veemente, ao defender o empréstimo dos livros lidos: "Não tem sentido um livro guardado; não tem sentido um livro que não é lido", e complementou: "Ele tá lá guardado, ele não tá cumprindo o papel dele”.

A internet seria o lugar onde encontrar livros de graça, sobretudo, especialmente os "clássicos" brasileiros - tanto piratas quanto em domínio público. Os conteúdos estão "na nuvem", independendo dos dispositivos. Esta seria uma característica e uma facilidade já desapegada da materialidade do livro impresso, a não ser que haja desejo de ter um volume, por qualquer razão ligada aos afetos ${ }^{31}$.

Em termos de negócio, os estudantes teceram comparações com o mercado da música, em que os conteúdos podem ser baixados ou simplesmente escutados, sem depender mais de CDs ou discos - algo que talvez possa ocorrer aos livros, embora a maioria não acreditasse nisso. Aparentemente, ao livro impresso caberá uma prática muito mais integrada com outras possibilidades, que é o que eles vêm fazendo, com alguma consciência, inclusive.

Além de tratar dos livros e da leitura de impressos e digitais, os estudantes que participaram desta investigação discorreram também, lateralmente, em relação a outras leituras de internet, como a de notícias, e a práticas de pesquisa escolar, além de falarem de suas aulas com e sem tecnologias digitais. Em alguns momentos, mencionaram a prática com audiolivros, alegando serem também uma alternativa interessante para "leitura", embora isso não tenha sido consenso entre eles.

31.Sobre "livros do coração", ver: ANDRADE, Roberta Manuela Barros de; SILVA, Erotilde Honório. Os projetos de democratização da leitura nos Livros do Coração. In: CONGRESSO BRASILEIRO DE CIÊNCIAS DA COMUNICAÇÃO, 38. 2015, Rio de Janeiro. Anais [...]. Rio de Janeiro: Universidade Federal do Rio de Janeiro, 2015. Disponível em: http://portalintercom org.br/anais/nacional2015/ lista_area_DT6-PE.htm Acesso em: 8 jan. 2019.

\section{LER E PESQUISAR NA WEB, BOAS E MÁS AULAS}

Durante nossos grupos focais com estudantes do ensino médio, soubemos que a maioria obteve seu primeiro celular aproximadamente aos 12-13 anos, geralmente um modelo simples, sem muitos recursos, grande parte das vezes usado, mais barato, até mesmo herdado dos pais ou de irmãos mais velhos. Disse uma aluna: "Nunca tive necessidade de ter um celular muito bom", no entanto, a entrada como estudante na instituição desencadeou uma série de necessidades de comunicação e de estudos, já que foi necessário "baixar PDFs e abrir e-mails toda hora".

O uso do e-mail foi atribuído a uma necessidade imposta ou trazida pelas práticas dos professores, que comumente enviavam material por esse canal. Grande parte dos estudantes não tinha conta de e-mail antes disso ou até tinha, mas apenas como requisito para abertura de contas em redes sociais. $\mathrm{O}$ uso do sistema acadêmico institucional também foi apontado como disparador da necessidade de ter um smartphone. 
A pesquisa escolar para trabalhos de várias matérias era feita prioritariamente pela internet, mas sempre com apoio do material didático impresso. Geralmente, o Google era a fonte preferencial, embora uma parte dos alunos soubesse ser ele apenas o motor da busca, e não a fonte propriamente. Essa consciência não foi generalizada, infelizmente. $\mathrm{O}$ site mais mencionado para pesquisa foi o Brasil Escola. E a pesquisa na web foi considerada fácil, pois tudo está "a distância de um clique".

Nas buscas no Google, uma estratégia emergiu nas conversas: "Eu pego sempre o terceiro que aparece lá". Grande parte dos colegas confirmou. A ideia é a de que o primeiro item listado pelo Google será sempre o que todos copiarão. Para pretensamente fugir disso, escolhe-se o terceiro. Em seguida, procede-se a uma "lidinha para ver se está tudo coerente", depois ao cotejo com anotações de caderno e "o que os professores disseram".

A Wikipédia, embora tenha sido citada, foi renegada por todos. "Os professores todos reclamam”, alegando ser um site não confiável porque é colaborativo, podendo sofrer mudanças feitas por "qualquer um"32. As tentativas de usar o Google Acadêmico, mais específico, foram frustradas, já que se trata de uma busca "específica demais", "científica mesmo", na maioria das vezes em inglês, língua que a maior parte dos alunos não domina para leituras mais especializadas. A despeito disso, uma aluna destacou: "mas melhora o seu inglês", caso o estudante insista.

E como separar o joio do trigo? Como lidar com notícias falsas (fake news)? Esse último é um dos assuntos mais recorrentes da atualidade e não escapou aos estudantes. Eles afirmaram ter algumas estratégias para evitar cair em notícias falsas, muito embora elas possam ser bem produzidas. Na ordem de importância, os alunos disseram que costumam estar atentos à autoria dos textos (atribuem ao autor parte considerável da confiança), ao ambiente de publicação (embora admitam vieses e cores ideológicas nem sempre explícitas), preferem textos sem muitos anúncios e pop-ups e verificam a grafia, aspectos normativos da linguagem em que os textos estão escritos. Segundo os jovens, textos com muitos erros não são dignos de confiança. Quando a mediadora questionou: "E se a notícia for muito bem feita, mas for falsa?", a turma respondeu: "Aí engana, né?".

Outras fontes muito mencionadas pelas turmas e usadas sem parcimônia foram as videoaulas, que são, para eles, a melhor forma de tirar dúvidas. Segundo disseram alguns adolescentes, a primeira tentativa de entender uma matéria é perguntando a um(a) colega. Se isso falhar, procuram então videoaulas no YouTube e documentários sobre o tema a ser estudado. As aulas avaliadas como mais "chatas", "soníferas" e "horríveis" são aquelas em que o(a) professor(a) emprega slides, isto é, PowerPoint e similares, especialmente quando os compõem com excesso de textos. Os estudantes acusaram alguns professores de não saberem produzir slides e de passarem horas lendo, o que os entediava e dificultava a aprendizagem. Para as turmas aqui focalizadas, as melhores aulas são as mais "simples", isto é, com boas explicações e interação ampla com os professores. Mesmo que sejam empregados o quadro/lousa
32. Em relevante e robusto trabalho, Carlos d'Andréa explica e analisa a colaboração na Wikipédia, jogando nova luz sobre o tema. Ver: D'ANDRÉA, Carlos Frederico de Brito. Processos editoriais auto-organizados na Wikipédia em português: a edição colaborativa de "Biografias de Pessoas Vivas". Tese (Doutorado em Estudos Linguísticos), Faculdade de Letras, Universidade Federal de Minas Gerais, Belo Horizonte, 2011. 
e papel, pretensamente tecnologias anacrônicas (segundo alguns discursos pró tecnologias digitais), os estudantes consideraram excelentes alguns modos de dar aulas, citando professores e disciplinas, inclusive inesperadas, em tese, para turmas de técnico, como filosofia ${ }^{33}$.

\section{CONSIDERAÇÕES FINAIS: VALORAÇÕES, PRÁTICAS E O MODO AVIÃO}

Será banal dizer que não se lê livro impresso porque pesa na mochila? Parece que não. Segundo nos relatou uma estudante, alguns professores permitem que os alunos tirem fotos das páginas a serem usadas para que eles não precisem carregar os volumes na mochila. Essa percepção, no entanto, é geradora de uma prática que leva a que os estudantes interpolem os usos que fazem de materiais impressos e digitais, sem tanta preocupação com concorrências, exclusividades, extinções e substituições. Para as práticas que demonstram, é tanto melhor que tenham opção e que possam selecionar o que desejam, conforme a demanda, a necessidade, a oportunidade ou o gosto, justamente conforme Moraes ${ }^{34}$ já desvelava em sua ampla pesquisa.

Não são as propagandas da TV, as necessidades empresariais ou os debates acadêmicos que se traduzem nas práticas reais e cotidianas das pessoas (consumidores, usuários, leitores...). O que eles fazem informa o debate de maneira mais precisa do que o que gostaríamos que eles fizessem. Seus argumentos soam, às vezes, banais; outras, consideráveis. A despeito disso, serão eles os seus critérios para escolher este ou aquele dispositivo, para esta ou aquela leitura, geralmente sem o tom de concorrência que vemos amiúde, sem a ideia necessariamente de ruptura ${ }^{35}$.

A leitura literária aparece, para estes jovens estudantes, como algo ligado

33.Esta afirmação pode ser um estereótipo de área, mas é assim que o senso comum considera as disciplinas oferecidas em relação aos cursos, em muitos casos.

34.MORAES, op. cit.

35.GUIMARÃES, Thayz; GONÇALVES, Márcio. Ruptura ou continuidade: a domesticação dos suportes de leitura e a presença marcante do impresso no digital. In CONGRESSO BRASILEIRO DE CIÊNCIAS DA COMUNICAÇÃO, 37., 2014, Foz do Iguacú. Anais [...]. Foz do Iguaçu: Unicentro, 2014. Disponível em: http://www.intercom. org.br/sis/2014/resumos/ R9-0819-1.pdf. Acesso em: 12 maio 2018. ao livro, tanto ao impresso quanto ao digital, mas conectada à escola e à vida, de maneira assimétrica. O livro que se deseja ler está fora do universo escolar. O livro escolar raramente vale a pena, bastando um PDF - que tem menos valor simbólico do que o volume impresso de capa bonita. A pessoa que tem livros impressos goza de prestígio, ainda. E é importante ser uma delas, para alguns, mas não para todos.

Para ser bom leitor é preciso gostar de "peneirar", segundo dizem esses jovens, mas "peneirar" pode ser arranjar estratégias frouxas, como a do "terceiro item da lista”. Ler livro é só se faltar wi-fi; ler livro é só se o tempo estiver radicalmente livre; ler literatura escolar ou "clássica" é somente atender a demandas que não viriam espontaneamente para a maioria, o que tem seu lado bom. Ler no celular distrai demais, e isso é claramente um problema. Quando o mediador sugere: "Já pensaram em pôr o celular no modo avião enquanto forem ler?", os estudantes se entreolham e riem. Não, não é o caso. Livro impresso é leitura "imersiva”, embora essa palavra seja encontrada no discurso sobre o digital com mais facilidade. Invertemos os valores, mas os alunos não caíram nessa. 
Segundo esses jovens, é o tempo investido em algo (por exemplo, na produção de um livro impresso ou na leitura de uma obra) que incrementa seu valor. $\mathrm{Na}$ analogia deles mesmos, é muito diferente dar os parabéns pelo aniversário de alguém por meio de um post em redes sociais ou dar os parabéns num telefonema ou fazendo uma visita. Quer dizer, não são os mesmos parabéns, e essa dedicação muda tudo em termos de tempo e valor simbólico. Na sequência das analogias que nossos estudantes fazem, é diferente dar um CD ou um vinil de música de presente a alguém e indicar uma canção no Spotify. Daí se presume o que eles valoram no livro em PDF e no livro impresso, embora tal noção de valor não os torne exatamente consumidores de livros literários, nem de um modo, nem de outro. São, sim, no entanto, leitores de tudo o que lhes cai na palma das mãos, mais por obrigação do que por gosto (infelizmente?).

Este trabalho, alinhado a resultados anteriores, como os das pesquisas de Mello Júnior ${ }^{36}$, Machiavelli ${ }^{37}$ e Moraes $^{38}$, buscou, por meio de questionário e grupos focais, uma aproximação com jovens estudantes do ensino médio a fim de refletir e construir uma compreensão dos seus modos interpolados e não-concorrentes de se relacionarem com os livros, impressos e digitais, pensando a circulação e a recepção, ainda que de maneira mais ligeira do que gostaríamos. Os usos sociais do livro, em suas tecnologias possíveis e contemporâneas, desenham as dinâmicas que podemos divisar hoje, mas que sabemos que estão em constante mudança.

\section{REFERÊNCIAS BIBLIOGRÁFICAS}

ANDRADE, Roberta Manuela Barros de; SILVA, Erotilde Honório. Os projetos de democratização da leitura nos Livros do Coração. In: CONGRESSO BRASILEIRO DE CIÊNCIAS DA COMUNICAÇÃO, 38., 2015, Rio de Janeiro. Anais [...]. Rio de Janeiro: Universidade Federal do Rio de Janeiro, 2015. Disponível em: http://portalintercom.org.br/anais/nacional2015/lista_ area_DT6-PE.htm. Acesso em: 8 jan. 2019.

CHARTIER, Roger. Cultura escrita, literatura e história: conversas de Roger Chartier com Carlos Aguirre Anaya, Jesús Anaya Rosique, Daniel Goldin e Antônio Saborit. Porto Alegre: Artmed, 2001.

CHARTIER, Roger. Os desafios da escrita. Tradução: Fúlvia M. L. Moretto. São Paulo: Editora Unesp, 2002.

D'ANDRÉA, Carlos Frederico de Brito. Processos editoriais auto-organizados na Wikipédia em português: a edição colaborativa de "Biografias de Pessoas Vivas". Tese (Doutorado em Estudos Linguísticos), Faculdade de Letras, Universidade Federal de Minas Gerais, Belo Horizonte, 2011.

DUARTE, Adriana Bogliolo Sirihal. Grupo focal online e offline como técnica de coleta de dados. Informação e Sociedade: Estudos, João Pessoa, v. 17, n. 1, p. 75-85, 2007. 
FITZPATRICK, Kathleen. Planned obsolescence: publishing, technology, and the future of the academy. New York: NYU Press, 2011.

GUIMARÃES, Thayz; GONÇALVES, Márcio. Ruptura ou continuidade: a domesticação dos suportes de leitura e a presença marcante do impresso no digital. In: CONGRESSO BRASILEIRO DE CIÊNCIAS DA COMUNICAÇÃO, 37., 2014, Foz do Iguacú. Anais [...]. Foz do Iguaçu: Unicentro, 2014. Disponível em: http://www.intercom.org.br/sis/2014/resumos/R9-0819-1. pdf. Acesso em: 12 maio 2018.

KIND, Luciana. Notas para o trabalho com a técnica de grupos focais. Psicologia em Revista, Belo Horizonte, v. 10, n. 15, p. 124-136, 2004.

MACHIAVELLI, Marina. A leitura de adolescentes: dados de um estudo exploratório. In: CONGRESSO BRASILEIRO DE CIÊNCIAS DA COMUNICAÇÃO, 40., 2017, Curitiba. Anais [...]. Curitiba: Universidade Positivo, 2017. Disponível em: http://portalintercom.org.br/anais/ nacional2017/resumos/R12-2127-1.pdf. Acesso em: 12 maio 2018.

MELLO JÚNIOR, José de. A recepção do e-book no Brasil: uma pesquisa quantitativa com leitores nativos e imigrantes digitais. In: CONGRESSO BRASILEIRO DE CIÊNCIAS DA COMUNICAÇÃO, 39., 2016, São Paulo: Anais [...]. São Paulo: Universidade de São Paulo, 2016. Disponível em: http:/ / portalintercom.org.br/anais/nacional2016/resumos/R11-2647-1. pdf. Acesso em: 12 maio 2018.

MORAES, André Carlos. Leitores multiplataforma: resultados de um estudo longitudinal com estudantes. In: CONGRESSO BRASILEIRO DE CIÊNCIAS DA COMUNICAÇÃO, 40., 2017, Curitiba. Anais [...]. Curitiba: Universidade Positivo, 2017. Disponível em: http://portalintercom.org.br/anais/ nacional2017/resumos/R12-0739-1.pdf. Acesso em: 12 maio 2018.

PRENSKY, Marc. Digital natives, digital immigrants part 1. On the Horizon, Berkley, v. 9 n. 5, p. 1-6, 2001.

RIBEIRO, Ana Elisa. Livro: edição e tecnologias no século XXI. Belo Horizonte: Moinhos/Contafios, 2018. (Coleção Pensar Edição)

SOARES, Magda. Novas práticas de leitura e escrita: letramento na cibercultura. Educação e Sociedade, Campinas, v. 23, n 31, p. 143-160, 2002.

SOARES, Magda. Letramento: um tema em três gêneros. 2. ed. Belo Horizonte: Autêntica, 2004. 